\title{
APPLICATION OF METAL COMPLEXES OF SCHIFF BASES AS AN ANTIMICROBIAL DRUG: A REVIEW OF RECENT WORKS
}

\author{
KUMBLE DIVYA*, GEETHA M. PINTO, ASHA F PINTO \\ Department of Post Graduate Studies and Research in Chemistry, St. Agnes College, Mangaluru 575002, Karnataka, India \\ Email: kumbledivya71088@gmail.com
}

Received: 28 Dec 2016, Revised and Accepted: 20 Mar 2017

\begin{abstract}
Schiff bases are versatile ligands which are synthesized from the condensation of primary amines with carbonyl groups. Synthesis of Schiff base transition metal complexes by using Schiff base as ligands appears to be fascinating in view of the possibility of obtaining coordination compounds of unusual structure and stability. These transition metal complexes have received exceptional consideration because of their active part in metalloenzymes and as biomimetic model compounds due to their closeness to natural proteins and enzymes. These compounds are very important in pharmaceutical fields because of their wide spectrum of biological activities. Most of them show biological activities including antibacterial, antifungal, antidiabetic, antitumor, antiproliferative, anticancer, herbicidal, and anti-inflammatory activities. The biological activity of the transition metal complexes derived from the Schiff base ligands has been widely studied. This review summarizes the importance, Scope and antimicrobial activities of Schiff base metal complexes.
\end{abstract}

Keywords: Schiff bases, Metal complexes, Microorganism and antimicrobial activity

(C) 2017 The Authors. Published by Innovare Academic Sciences Pvt Ltd. This is an open access article under the CC BY license (http://creativecommons.org/licenses/by/4.0/) DOI: http://dx.doi.org/10.22159/ijcpr.2017v9i3.19966

\section{INTRODUCTION}

Synthesis of metal complexes attained increasing interest owing to their versatile coordination behaviour and in the understanding of molecular processes $[1,2]$. Metal complexes are of significant attention in terms of its structural and coordination chemistry. They display diverse chemical, optical and magnetic properties by tailoring with different ligands. In specific, the study of metal complexes of Schiff base (SB) ligands appears to be fascinating in terms of unusual structure and stability. SB complexes are considered to be among the most important stereochemical models in transition metal coordination chemistry due to their preparative accessibility and structural variety $[3,4]$. Structurally, a SB (also known as imine or azomethine) is a nitrogen analogue of an aldehyde or ketone in which the carbonyl group $(>C=0)$ is replaced by an imine or azomethine group, (Aromatic aldehydes especially with an effective conjugation system) [5]. Transition metal complexes which usually contain nitrogen, sulphur or oxygen as ligand atoms have become increasingly important because these SB can bind with different metal centres involving various coordination sites and allow successful synthesis of metal complexes [6]. The high affinity for the chelation of the SB towards the transition metal ions is utilized in preparing their solid complexes [7]. The interaction of these donor ligands and metal ions gives complexes of different geometries and literature survey reveals that these complexes are biologically active compounds. Thus, in recent years SB and their metal complexes have attained much attraction because of their extensive biological activities $[8,9]$.

These complexes have also received exceptional consideration because of their active part in metalloenzymes and as biomimetic model compounds due to their closeness to natural proteins and enzymes [10]. The research field dealing with metal complexes is very broad and includes a number of interdisciplinary areas such as bioinorganic chemistry, catalysis, photochemistry and magneto chemistry [11]. The advances in inorganic chemistry provide better opportunities to use metal complexes as therapeutic agents. Research has shown significant progress in utilization of SB transition metal complexes as drugs to treat several human diseases. The use of SB transition metal complexes as therapeutic compounds has become more and more pronounced. Synthetic SB metal complexes are an emerging class of compounds with varying chemistry, different molecular topologies and sets of donor atoms. It is a known fact that $\mathrm{N}$ atom plays a key role in the coordination of metals as the active site of numerous metallobiomolecules [12-14]. These complexes offer a great diversity in their action; as antibacterial [15-18], antifungal [19-22], anticancer [23-25] and anti-inflammatory agents [26-29]. Due to the demand of new metal-based antibacterial compounds, metallorganic chemistry is becoming an emerging area of research [30].

Important characteristics that can be correlated with good antimicrobial activities are the lipophilicity and penetration of complexes through the lipid membrane. Microorganisms have existed on the earth for more than 3.8 billion years and exhibit the greatest genetic and metabolic diversity. For the maintenance and sustainability of the ecosystem these microorganisms have an important role and thus they are considered as an essential component of the biosphere [31]. Currently, antimicrobial resistance among bacteria, viruses, parasites, and other disease-causing organisms is a serious threat to infectious disease management [32]. The actions of antimicrobial agents are studied by understanding its mechanism of resistance. Antimicrobial agents show a minimal effect or no effect on host function when it's acted upon vital microbial functions. Different antimicrobial agents act in different ways. The mechanism of action of antimicrobial agents can be categorised on the basis of the structure of bacteria or the function that is affected by the agents and these include the following:

_ Inhibition of the cell wall synthesis.

_ Inhibition of ribosome function.

_ Inhibition of nucleic acid synthesis.

_ Inhibition of folate metabolism.

_ Inhibition of cell membrane function.

Resistance can be described in two ways:

a) intrinsic or natural resistance whereby microorganisms naturally do not possess target sites for the drugs and therefore the drug does not affect them or they naturally have low permeability to those agents because of the differences in the chemical nature of the drug and the microbial membrane structures especially for those that require entry into the microbial cell in order to effect their action or

b) Acquired resistance whereby a naturally susceptible microorganism acquires ways of not being affected by the drug. 
Overall, the activities of all the complexes obtained were found to be moderate even though higher concentrations were applied. In order to survive, microorganisms were increasingly becoming more resistant against the arsenal antimicrobial agents to which they were being targeted [33-34].

\section{Test methods in detecting antimicrobial resistance}

Selection of the appropriate method will depend on the intended degree of accuracy, convenience, urgency, availability of resources, availability of technical expertise and cost. Many antimicrobial susceptibility testing methods can be followed but each has their own advantages and disadvantages.

Different methods are available to estimate the antimicrobial activity of metal complexes, for example, automated methods Mechanism-specific tests such as beta-lactamase detection test and chromogenic cephalosporin test. Genotypic methods such as PCR and DNA hybridization methods. The two most commonly used methods in laboratories are the agar disk diffusion method and the broth microdilution method [35].

This review's aim is to at have an insight on the application of transition metal complexes of $\mathrm{SB}$ as an antimicrobial agent. Literature survey reveals that metal complexes have a wide range of application as an antimicrobial drug. In the present paper, the summary of the reported work on antimicrobial activity of SB metal complexes are briefly discussed.

Three novel heteroaromatic hydrazone derivatives of 5-methyl-2furfural hydrazone glyoxime, 3-acetylpyridine hydrazone glyoxime and 4-acetylpyridine hydrazone glyoxime and their $\mathrm{Ni}(\mathrm{II}), \mathrm{Cu}(\mathrm{II})$ and Co(II) complexes were prepared. Microbial activity of complexes was evaluated using the disc diffusion method against different species of bacteria and yeasts. Complexes were tested against stains of Bacteria like (B. thuringiensis, B. cereus ATCC 11778, Streptococcus pneumoniae ATCC 49617), B. cereus ATCC 11778, B. thuringiensis, $S$. pneumoniae ATCC 49617 and yeasts like S. cerevisiae ATCC 9763 and C. tropicalis C. utilis and against the yeasts (Saccharomyces cerevisiae ATCC 9763, Candida utilis and Candida tropicalis) [15].

Co(II), Ni(II), Zn(II) and Cu(II) complexes of (3E)-3-[(2-\{(E)-[1-(2,4dihydroxyphenyl)ethylidene]amino\}ethyl)imino]-1-phenylbutan-1one (DEPH2) derived from ethylenediamine, 2',4'-dihydroxyacetophenone and 1-phenylbutane-1,3-dione have been synthesized and screened to establish their potential as antibacterial agents, The ligand and their metal complexes were screened for antibacterial activity against Gram (+) and Gram (-) bacteria by the agar well diffusion method. In general, metal(II) complexes have been shown to be more effective than the free ligands and the same was observed in this study, i.e., that the complexes are more active than the parent SB ligand. The $\mathrm{Cu}(\mathrm{II})$ complex was found to show bactericidal activity against $B$. cereus, $S$. aureus and $S$. flexineri and bacteriostatic activity against $S$. faecalis, $P$. aeruginosa, and E. Coli [16].

Novel Co(II) complexes of SB 2-amino-4-nitrophenol-N-salicylidene with some amino acids were synthesised. The SB and mixed ligand complexes were preliminary scanned against various strains of microbes to study their biological effect. It's evident from the obtained result that microbial activity of metal complexes was found to be higher than the free ligand [17].

A new heterocyclic SB ligand bis(2-(pyridin-2-ylimino)phenyl)-4,4'(diazene-1,2-diyl)dibenzoate (BPPD, L) and its metal complexes with divalent transition metal ions viz., $\mathrm{Co}(\mathrm{II}), \mathrm{Ni}(\mathrm{II}), \mathrm{Cu}(\mathrm{II})$ and $\mathrm{Zn}(\mathrm{II})$ have been synthesized and screened for the antibacterial activities towards bacteria Staphylococcus aureus (gram positive) and Escherichia coli (gram-negative), and antifungal activities towards fungi Aspergillus niger and Candida albicans. The results showed that the complexes have higher antimicrobial activities than the ligand. The order of antimicrobial activities was $\mathrm{Cu}(\mathrm{II}) \mathrm{L}>\mathrm{Zn}(\mathrm{II})$ $\mathrm{L}>\mathrm{Ni}(\mathrm{II}) \mathrm{L}>\mathrm{Co}(\mathrm{II}) \mathrm{L}>\mathrm{L}[18]$.

A new SB containing 2-[(2-chloro-4-methylbenzylidene) amino] pyridin-4-ol with some transition metal ions with general formula of the complexes [M(L2)nH2O] [ where $\mathrm{M}=\mathrm{Mn}(\mathrm{II}), \mathrm{Co}(\mathrm{II}), \mathrm{Ni}(\mathrm{II}) \mathrm{Cu}(\mathrm{II})$, $\mathrm{Zn}(\mathrm{II}), \mathrm{Pt}(\mathrm{II})$ and $\mathrm{L}=2$-[(2-chloro-4-methylbenzylidene) amino] pyridin-4-ol ] were synthesized and tested against some bacteria. It was showed that Pt (II) complexes are more active towards all bacteria. Bacteria like $E$ coli, $S$ flexenari, $P$ aeruginosa and $S$ typhi and two Gram-positive bacteria like $B$ subtilis and $S$ aureus strains were tested using agar gel diffusion method [36].

New metal complexes of the ligand 2-[1H-Pyrrol-2-ylimino methyl]5-phenyl-1, 3,4-oxadiazol (HL) with the metal ions Co(II), Ni(II) and $\mathrm{Cu}(\mathrm{II})$, were prepared in an alcoholic medium. The SB were condensed by using [Pyrrolcarboxaldehyde] with [2-amino-5[phenyl-1, 3, 4-oxadiazole] in an alcoholic medium. As the SB prepared was a tridentate ligand, it was used for forming complexes with $\mathrm{Co}^{+2}, \mathrm{Ni}^{+2}, \mathrm{Cu}^{+2}$ and $\mathrm{Zn}^{+2}$ ions of type $\mathrm{M}$ (HL). All the synthesised $\mathrm{SB}$ and their metal complexes were tested for their antimicrobial activity. The antimicrobial activity of these compounds was determined by the agar diffusion method. Staphylococcus aureus, Escherishia coli, Pseudononasaeroginosa and Cndidaalbicans bacteria were used to show the biological activities of the ligand and its complexes [37].

The condensation reaction of malonoyldihydrazide and 2aminobenzaldehyde carried out for the synthesis of SB. 3Dtransition metals like $\mathrm{Cu}(\mathrm{II}), \mathrm{Ni}(\mathrm{II}), \mathrm{Zn}(\mathrm{II})$ and oxovanadium (IV) were complexed with the newly synthesised SB ligand. Antibacterial activity of metal complexes was examined against species like Staphylococcus Aureus, Bacillus subtilis, Pseudomonas aeruginosa, and Escherichia coli. It was observed that the metal complexes were biologically active than free ligand [38].

Metal-ligand complex of $\mathrm{Co}(\mathrm{II}), \mathrm{Ni}(\mathrm{II}), \mathrm{Cu}(\mathrm{II})$ and $\mathrm{Mn}(\mathrm{II})$ and $\mathrm{SB}$ derived from a pyridine- 2 aldehyde, furfur aldehyde or thiophene- 2 carboxy aldehyde with vinyl aniline were prepared and tested for antibacterial activity. The paper disc diffusion method was used for the determination of antibacterial activity against bacterial strains likeEscherichia coli, Staphylococcus aureus, Klebsiella and Psuedomonas and Candida albicans or Candida kruse. Antibacterial activity of ligand was enhanced while complexing with the metal atom [39].

New SB namely \{1-[(5-bromo-2-hydroxy-benzylidene)-amino]-4phenyl-2-thioxo-1,2-dihyro-pyrimidin-5-yl\}-phenyl-methanone, was synthesized from $\mathrm{N}$-amino pyrimidine-2-thione and 5bromsalicylaldehyde. Synthesized SB was used as a ligand for the preparation of metal complexes from acetate salts of $\mathrm{Cu}(\mathrm{II}), \mathrm{Ni}(\mathrm{II})$, $\mathrm{Co}(\mathrm{II}), \mathrm{Pd}(\mathrm{II})$, and $\mathrm{PtCl}_{2}$ in methanol. The SB and the $\mathrm{Cu}(\mathrm{II})$ and $\mathrm{Co}(\mathrm{II})$ complexes showed good biological antibacterial activity against four gram-positive (S. aureus ATCC 6538 , S. aureus ATCC 25923 , B. cereus ATCC 7064, and M. luteus ATCC 9345) and one gram-negative (E. coli ATCC 4230) bacteria, Ampicillin trihydrate was used as the reference antibacterial agent. It was reported in their studies that the antibacterial activities of all of the complexes were greater than those of the free SB ligand [40].

Tetradentate SB ligands derived from the Knoevenagel condensation of $\beta$-ketoanilides and furfural with $o$-phenylenediamine and diethyl malonate and their $\mathrm{Cu}(\mathrm{II})$ complexes showed antibacterial activity against Escherichia coli, Salmonella typhi, Staphylococcus aureus, Klebsiella pneumoniae and Pseudomonas aeruginosa. And also the revived in their result that bidentate complexes of $\mathrm{Co}(\mathrm{II}), \mathrm{Cu}(\mathrm{II})$ and $\mathrm{Cd}(\mathrm{II})$ with benzofuran-2-carbohydrazide and benzaldehyde [BPMC] or 3,4-dimethoxybenzaldehyde [BDMePMC] showed biological activities but $\mathrm{Cu}(\mathrm{II})$ complex of [BPMC] and [BDMeOPMC] are more active against $S$. aureus as compared to $\mathrm{Co}(\mathrm{II})$ and $\mathrm{Cd}(\mathrm{II})$ complexes.

The bidentate ligand of 2-[(2-[1-(hydroxyphenyl) ethyl] aminophenyl) ethanimidoyl] phenol derived from ophenylenediamine are effective against Bacillus cereus, Staphylococcus aureus and E. Coli. Antibacterial activity of the Clomiphene citrate copper complex has been determined against $E$. coli, Staphylococcus aureus and Xanthomonas vesicatoria by. The mixed ligand complexes of $\mathrm{Cu}$ (II) with SBs N-(2-hydroxy-1naphthylidene)-4-chloroaniline (L1) and N-(2-hydroxybenzylidene)2,3-dimethylaniline (L2) reported to show some antibacterial activity to certain extent against E. coli, S. aureus, B. subtilis, and $S$. typhi., but their complexes exhibit comparatively greater amount of activity against these bacteria [41]. 
New SB ligand were synthesised from benzofuran-2-carbohydrazide and 4-methyl-thiobenzaldehyde. Prepared SB was used as a selective ligand for the complexation of metals like $\mathrm{Cu}(\mathrm{II}), \mathrm{Co}(\mathrm{II}), \mathrm{Ni}(\mathrm{II}), \mathrm{Zn}(\mathrm{II})$, $\mathrm{Cd}(\mathrm{II}), \mathrm{Hg}(\mathrm{II})$. This complex was tested against the bacteria namely $E$. coli, and $S$. aureus using agar diffusion method. Studies revealed that $\mathrm{Cu}(\mathrm{II})$ and $\mathrm{Hg}$ (II) complexes showed good activity against bacteria $E$. coli and $S$. aureus while $\mathrm{Ni}(\mathrm{II}), \mathrm{Co}(\mathrm{II})$ and $\mathrm{Cd}(\mathrm{II})$ complexes show moderate activity against both bacteria $E$. coli and $S$. Aureus [42].

Transition metals like Co(II), Ni(II), Zn(II) and $\mathrm{Cu}(\mathrm{II})$ were used for the preparation of biologically active metal complexes. SB namely (3E)-3-[(2-\{(E)-[1-(2,4-dihydroxyphenyl)ethylidene]amino\} ethyl) imino]-1-phenylbutan-1-one (DEPH2) derived from ethylenediamine, 2',4'-dihydroxyacetophenone and 1-phenylbutane-1,3dione have been used as a active ligand. The ligand and their metal complexes were screened for antibacterial activity against Gram (+) and Gram (-) bacteria. Three Gram-positive viz. Staphylococcus aureus (ATCC 25923), Streptococcus faecalis (ATCC 29212), Bacillus cereus (ATCC 10702), and three Gram-negative bacteria viz. Pseudomonas aeruginosa (ATCC 19582), Escherichia coli. (ATCC 25922) and Shigella flexineri (KZN) using agar diffusion method. The standards used were Ciprofloxacin and amoxicillin [43].

Nano-sized SB complexes of Mn(II), Co(II), Ni(II), Zn(II) and Cu(II) were synthesized and it was screened against gram-positive (Staphylococcus aureus) and gram-negative (Escherichia coli). Results indicates that all the SB complexes individually exhibited varying degrees of inhibitory effect on the growth of the tested bacterial species and the SB complexes were more pronounced when coordinated with the metal ions. The biological activity of the complexes follow the order: Antibacterial effect: Co(II)> $\mathrm{Zn}(\mathrm{II})>\mathrm{Cu}(\mathrm{II})>\mathrm{Ni}(\mathrm{II})>\mathrm{Mn}$ (II) and Antifungal effect: $\mathrm{Cu}(\mathrm{II})>$ $\mathrm{Co}(\mathrm{II})>\mathrm{Zn}=\mathrm{Mn}=\mathrm{Ni}[44]$.

New titanium (IV) complexes were synthesized by reacting $\mathrm{TiCl}_{4}$ with different SB ligand like tetracycline hydrochloride, Streptomycin, Cefixime and ampicillin in fixed molar ratio (1:2). These complexes were examined for their biological activity against pathogenic bacterial strains i.e. Bacillus cereus MTCC 6728, Micrococcus luteus MTCC 1809 , Staphylococcus aureus MTCC 3160, Staphylococcusepidermidis MTCC 3086, Aeromonas hydrophila MTCC 1739, Aclaligenes faecalis MTCC 126, Shigella sonnei MTCC 2957, Klebsiella pneumoniae MTCC 3384, Pseudomonas aeruginosa MTCC 1035, and Salmonella typhimurium MTCC 1253. They reported that metal complexes have more biological activity than their parent SB Preliminary in vitro antibacterial study indicated that all the complexes obtained showed a moderate activity against the tested bacterial strains and a slightly higher activity compared to the ligand [45].

New SB was prepared from piperonal and diamine compounds (ethane-1,2-diamine, propane-1,3-diamine, butane-1,4-diamine). These ligands were Complexed with Co(II) chloride. The ligands and metal complexes were screened for their antimicrobial activities against gram-positive bacteria and gram negative bacteria. It was found that they were biologically active. All ligand showed high activity compared to the complexes due to the chalation hold the azomethine groups in complexes by coordination bonds with metal ion leading low inhibition in biological activity [46].

Metal complexes of $\mathrm{Fe}(\mathrm{II}), \mathrm{Co}(\mathrm{II}), \mathrm{Ni}(\mathrm{II}), \mathrm{Cu}(\mathrm{II})$ and $\mathrm{Zn}$ (II) were synthesized by complexation of SB derived from the condensation of 2-thiophenecarboxaldehyde with 2-aminipyridine and 2thienylmethylidine. Obtained complexes were examined for their antibacterial activity on E. coli, Staphylococcus aureus and Pseudomonas aeruginosa using the paper disk diffusion method. Metal chelates showed very good antibacterial activity than free SB. E. coli was inhibited to a greater degree by the Co(II) and Fe(II) complexes. From the result, it's clear that the complexes formed by Co(II) and Fe(II) can used for the treatment of some common diseases caused by E. Coli [47].

\section{CONCLUSION}

Development of SB transition metal complexes as drugs is not an easy task; considerable effort is required to get a compound of interest. Beside all these limitations and side effects, transition metal complexes are still the most widely used chemotherapeutic agents and make a large contribution to medicinal therapeutics.

\section{CONFLICT OF INTERESTS}

\section{Declare none}

\section{REFERENCES}

1. Shamsipur M, Ghiasvand AR. Solid phase extraction of ultra trace copper(II) using octadecyl silica membrane disks modified by a naphthol derivative schiff's base. Anal Chim Acta 2000;408:271-7.

2. Reddy KK, Sayaji R, Biyyala SR. Synthesis and characterization and biological activities of hydrazones. Int J Innovative Res Sci Eng Technol 2015;4:18944-52

3. Qiu M, Liu G, Yao X, Guo M, Pan G, Zheng ZC. Copper(II)-schiff base complexes as catalysts for asymmetric cyclopropanation of styrene. Chin J Catal 2001;22:77-80.

4. Zhuo-Hong Yang, Li-Xin Wang, Zheng-Hong Zhou, Qi-Lin Zhou, Chu-Chi Tang. Synthesis of new chiral schiff bases and their application in the asymmetric trimethylsilyl cyanation of aromatic aldehydes. Tetrahedron Asymmetry 2001;12:1579-82.

5. Jose ES, Edward RS, Cavalheirob ETG. Synthesis and characterization of schiff bases from chitosan and salicylaldehyde derivatives. Carbohydrates Polymer 2005;60:277-82.

6. Alexander V. Design and synthesis of macrocyclic ligands and their complexes of lanthanides and actinides. Chem Rev 1995;95:273-342.

7. Quiruga AG, Ranninger CN. Review contribution to the SAR field of metallated and coordination complexes: studies of the palladium and platinum derivatives with selected thiosemicarbazones as antitumoral drugs. Coord Chem Rev 2004;248:119-33.

8. Douglas XW, Anthony E. Thiosemicarbazone complexes of copper(II): structural and biological studies. Coord Chem Rev 1993;123:49-71.

9. Tuo W, Zijian G. Copper in medicine: homeostasis, chelation therapy and antitumor drug design. Curr Med Chem 2006;13:525-37.

10. Lobana TS, Sharma R, Gagandeep B, Sonia K. Bonding and structure trends of thiosemicarbazone derivatives of metals an overview. Coord Chem Rev 2009;253:977-1055.

11. Pietro AV, Sergio T. The challenge of cyclic and acyclic schiff bases and related derivatives. Coord Chem Rev 2004;248:1717-2128.

12. Supuran CT, Barboiu M, Luca C, Pop E, Brewster ME, Dinculescu A. Carbonic anhydrase activators. Part 14. Syntheses of mono and bispyridinium salt derivatives of 2-amino-5-(2aminoethyl)-and 2-amino-5-(3-aminopropyl)-1,3,4-thiadiazole and their interaction with isozyme II. Eur J Med Chem 1996;31:597-606.

13. Gaur S. Physico-chemical and biological properties of Mn(II), $\mathrm{Co}(\mathrm{II}), \mathrm{Ni}(\mathrm{II})$ and $\mathrm{Cu}(\mathrm{II})$ chelates of schiff bases. Asian J Chem 2003;15:250-4.

14. Michael JG, Carolyn B, Barb JK, Steven M. Swaney W, Gary. Novel 1,5-Diphenylpyrazole nonnucleoside hiv-1 reverse transcriptase inhibitors with enhanced activity versus the delavirdine-resistant p236l mutant: lead identification and SAR of 3-and 4-substituted derivatives. J Med Chem 2005;43:1034-40.

15. Ilknur B, Esin P, Halil B. Synthesis, characterization and antimicrobial activities of vicdioxime derivatives containing heteroaromatic hydrazone groups and their metal complexes. Int J Sci Technol 2013; 7:26-41.

16. Ikechukwu Pe, Ajibade PA. Synthesis, characterization and biological studies of metal(ii) complexes of (3E)-3-[(2-\{(E)-[1(2,4-Dihydroxyphenyl) ethylidene]amino\}ethyl)imino]-1phenylbutan-1-one schiff base. Molecules 2015;20:9788-802.

17. Ajay RP, Kamini JD, Raut VR Patil, Lokhande RS. Synthesis, characterization and biological activity of mixed ligand Co(II) complexes of schiff base 2-amino-4-nitrophenol-n-salicylidene with some amino acids. J Chem Pharm Res 2012;4:1413-25. 
18. Hemant K, Chaudhary RP. Biological studies of a novel azo based heterocyclic schiff base and its transition metal complexes. Der Chem Sin 2010;1:55-61.

19. Chohana Z, Sajjad HS, Moulay HY, Taibi BH. Metal based biologically active compounds: Design, synthesis, and antibacterial/antifungal/cytotoxic properties of triazolederived schiff bases and their oxovanadium (IV) complexes. Eur J Med Chem 2010;45:2739-47.

20. Aliasghar J, Dariush E, Chanaz S, Jean MB. Synthesis, antibacterial, antifungal and antiviral activity evaluation of some new bis-schiff bases of isatin and their derivatives. Molecules 2007;12:1720-30.

21. Rajavel R, Enthil MV, Anitha C. Synthesis, physical characterization and biological activity of some schiff base complexes. Eur J Chem 2008;5:620-6.

22. Bernadette SC, Brian D, Denise A, Egana KK, Georgina R. Anticancer and antifungal activity of copper(II) complexes of quinolin-2(1H)-one-derived Schiff bases. Inorganic Chim Acta 2010;363:4048-58.

23. Parasha RK, Sharma RC, Govind M. Biological activity of some schiffbases and their metal complexes. Biol Trace Element Res 1989;23:145-50.

24. Gaowen Y, Xiaoping X, Huan T, Zhao C. Synthesis and antitumor activity of schiff base coordination compounds. Chinese J Appl Chem 1995;12;13-7.

25. Maria CC, Michela B, Alessandro D, Elias M, Antonio P. Synthesis and antimicrobial activity of novel arylideneisothio semicarbazones. Pharmaceutical 2000;55:93-8.

26. Blahova M, Sokolík J, Sedlackova S, Burianova E, Mlynarcik D. Antimicrobial activity of diazole-(N-salicylidene-L-alphaalaninato)-copper complexes. Ceskoslovenska Farmacie 1993;42:137-40.

27. Blahova M, Tumova M. Anti-inflammatory activity of aqua(aryloxyacetato)copper(II) complexes. Pharmazie 1994;49:373-4.

28. Gladiola T, Mihai N, Lenuta P. Synthesis and biological evaluation of some new schiff bases and their $\mathrm{Cu}(\mathrm{II})$ and $\mathrm{Mg}(\mathrm{II})$ complexes. Afr J Pharm Pharmacol 2013;7:1225-30.

29. Abhishek K, Fernandes J, Pankaj K. Synthesis, antimicrobial and anti-inflammatory studies of some novel schiff base derivatives. Int J Drug Development Res 2014;6:165-7.

30. Dun E. Antifungal resistance in yeast vaginitis. Yale J Biol Med 1999;72:281-5.

31. Fluit C, Maarten RV, Franz-Josef S. Molecular detection of antimicrobial resistance. Clin Microbiol Rev 2001;14:836-71.

32. Yeaman MR, Yount NY. Mechanisms of antimicrobial peptide action and resistance. Pharmacol 2003;55:27-55.

33. Yousif E, Adil H, Majeed A, Graisa A, Farina Y. Structure and fungicidal activity of some diorganotin(IV) with benzamidophenylalanine. Arabian J Chem 2009;4:39-42.

34. Yousif E, Adil H, Farina Y. Synthesis and characterization of some metal Ions with 2-amino acetate benzothiazole. J Appl Sci Res 2010;6:879-82.
35. Y Win, Yousif E, Majeed A, Ha S. Synthesis, characterization and in vitro antimicrobial activity of $\mathrm{Co}(\mathrm{II}), \mathrm{Cu}(\mathrm{II}), \mathrm{Zn}(\mathrm{II}), \mathrm{Cd}(\mathrm{II})$ and $\mathrm{Sn}(\mathrm{II})$ ions with $\{[5$-(4-bromophenyl)-1,3,4-oxadiazol-2yl] thio\}acetic acid. Asian J Chem 2011;23:5009-12.

36. Asif NK, Ajay P, Sharad T, Jagannath JK, Lokhande MV. Antibacterial activity of 2-[(2-chloro-4-methylbenzylidene) amino] pyridin-4-ol and its some transitional metal ion complexes. IOSR J Appl Chem 2014;7:14-20.

37. Nazk MA, Shaalanand ND, Sahar S. Synthesis, spectroscopic, thermodynamic and biological activity studies of schiff base and metal complexes derived from 2-[ 1h-pyrrol-2-ylimino methyl]-5-phenyl-1,3,4-oxadiazole. Global J Sci Frontier Res: B Chem 2015;15:14-8.

38. Shridhar SR, Pandeya SN. Synthesis and anti-HIV activity of some isatin derivatives E. De Clercq Ball Chimico Farmaceutico 2001;140:302-5.

39. Pratibha MSJ, Vatsala P, Uma V. Biologically active Co (II), Ni (II), $\mathrm{Cu}$ (II) and Mn(II) Complexes of Schiff Bases derived from Vinyl aniline and Heterocyclic Aldehydes. Int J Chem Technol Res 2009;1:225-32.

40. Mehmet G, Mehmet S, Ismet B. Synthesis, characterization, and antimicrobial activity of a new pyrimidine schiff base and its $\mathrm{Cu}(\mathrm{II}), \mathrm{Ni}(\mathrm{II}), \mathrm{Co}(\mathrm{II}), \mathrm{Pt}(\mathrm{II})$, and $\mathrm{Pd}(\mathrm{II})$ complexes. Turkish J Chem 2012;36:189-200.

41. Rishu K, Harpreeth K, Brij KK. Applications of copper-schiff base complexes: a review. Sci Rev Chem Commun 2013;3:1-15.

42. MB Halli MB, Ravindra SM, Sumathi RB, Shivakumar K. Synthesis, spectroscopic characterization and biological activity studies of schiff base metal complexes derived from N'(4-(methylthio) benzylidene)benzofuran-2-carbohydrazide. Der Pharm Lett 2013;5:182-8.

43. Ikechukwu PE, Peter AA. Synthesis, characterization and biological studies of metal(ii) complexes of (3E)-3-[(2-\{(E)-[1(2,4-Dihydroxyphenyl) ethylidene]amino\}ethyl)imino]-1phenylbutan-1-one schiff base. Molecules 2015;20:9788-802.

44. Omar BI, Mahmoud AM, Moamen SR. Nano sized schiff base complexes with $\mathrm{Mn}(\mathrm{II}), \mathrm{Co}(\mathrm{II}), \mathrm{Cu}(\mathrm{II}), \mathrm{Ni}(\mathrm{II})$ and $\mathrm{Zn}(\mathrm{II})$ metals: synthesis, spectroscopic and medicinal studies. Can Chem Trans 2014;2:108-21.

45. Raj K, Sheetal T. Syntheses and biological creening of schiff base complexes of titanium(IV). Chem Eng Transactions 2013;32:1801-6.

46. Mouayed YK, Abduljleel MA. Synthesis, characterization and biological studies of schiff bases derived from piperonal and their complexes with cobalt (II). Der Pharma Chem 2014;6:88-100.

47. Spinu C, Pleniceanu M, Cristian T. Biologically active transition metal chelates with a 2-thiophenecarboxaldehyde derived schiff base: synthesis, characterization, and antibacterial properties. Turkish J Chem 2008;32:487-93.

\section{How to cite this article}

- Kumble Divya, Geetha M Pinto, Asha F Pinto. Application of metal complexes of schiff bases as an antimicrobial drug: a review of recent works. Int J Curr Pharm Res 2017;9(3):27-30. 